\title{
† Mme R.-M. FRICK-CRAMER
}

C'est avec un vif regret que l'on a appris la fin soudaine de Mme R.-M. Frick-Cramer, qui joua, dans le monde de la CroixRouge, un rôle éminent.

Elle fut nommée membre du CICR en I9I8, mais, dès I9I4, elle avait participé à la création de l'Agence internationale de Genève et partagé, avec M. J. Chenevière, la direction du service des prisonniers de guerre alliés. Sa préoccupation dominante devint dès lors que les prisonniers de guerre et les civils victimes des hostilités fussent mieux protégés.

Lorsque éclata le second conflit mondial, elle se dévoua entièrement au service de l'Agence centrale des prisonniers de guerre. De I940 à I946, ses connaissances juridiques et pratiques furent précieuses au Comité international, qui trouva en elle une personnalité d'une intelligence remarquable et d'une générosité active. Dans les séances et les commissions juridiques ou techniques, sa vaste expérience conférait à ses avis une grande autorité.

Cette femme, d'autre part si modeste, se consacra à la cause des victimes qu'aucune convention ne protégeait alors: les internés civils. Elle s'efforça, avec ses collègues, d'obtenir qu'ils fussent mis au bénéfice des dispositions applicables aux militaires en captivité. Elle fit rayonner autour d'elle sa confiance dans l'efficacité de l'idéal humanitaire.

La Revue internationale eut l'occasion de rappeler les mérites très grands de Mme Frick-Cramer lorsque celle-ci démissionna et 
fut nommée, en 1946 , membre honoraire du Comité international. ${ }^{1}$ Dans le même numéro fut publiée une bibliographie d'ouvrages et d'articles, afin de montrer la haute valeur de la contribution de Mme Frick-Cramer à l'histoire de la Croix-Rouge et au droit humanitaire.

Connaissant tout l'appui que Mme Frick-Cramer lui a apporté durant plus de trente années, avec tant de sagesse et de dévouement, le Comité international lui gardera un souvenir fidèle et profondément reconnaissant. Il exprime à M. Edouard-A. Frick, qui fut longtemps délégué général du CICR, ainsi qu'à sa famille, l'expression de la vive sympathie de l'institution.

\footnotetext{
1 Novembre 1946.
} 